\title{
ГРАЖДАНСКО-ПРАВОВАЯ ОТВЕТСТВЕННОСТЬ ЗА ЭКОЛОГИЧЕСКИЙ ВРЕД: ПРОБЛЕМЫ ТЕОРИИ И ПРАКТИКИ
}

\begin{abstract}
Аннотация: Предметом исследования являются проблемы применения института гражданско-правовой ответственности за вред, причиненный окружающей среде. Автор ставит вопрос о пределах действия принципов и норм гражданского законодательства при регулировании экологических отношений. Анализируя категорию «экологический вред» с позиции охраняемых законом интересов, акцентирует внимание на том, что причинение вреда природной среде одновременно посягает как на публичные экологические интересы, так и на имущественные права частных лиц. При возникновении конфликта интересов возникает проблема приоритета защиты. В ходе исследования были использованы какобщенаучные, так и частно-научные методы научного познания: диалектический, формально-логический, формально-юридический, сравнительно-правовой. На основе анализа действующего законодательства и правоприменительной практики доказывает, что институт возмещения экологического вреда не выполняет свою главную - компенсационно-восстановительную - функиию. Делает вывод о необходимости ограничить применение при рассмотрении требований о возмещении экологического вреда такого способа защиты прав как возмещение убытков.

Abstract: The problems of the implementation of institution of civil-legal responsibility for damages to the environment become the subject of this research. The author presents the issue of the limitation of principles and norms of the civil legislation in regulation of the environmental relations. Analyzing the category "environmental harm" from the position of interests protected by law, the author focuses her attention on the fact that inflicting damage to the environment simultaneously infringes on both, the public environmental interests, and the property rights of private parties. In cases of conflict of interests often emerges the problem of prioritizing protection. Based on the analysis of the acting legislation and legal practice it is evident that the institution for reimbursement of environmental damages does not fulfill its main compensational and restorative function. The author draws a conclusion that in addressing the requests for compensation of environmental harm it is necessary to limit the type of protect such as reimbursement of losses.

Ключевые слова: Гражданская ответственность, экологический вред, окружающая среда, убытки, натуральная реституция, возмещение вреда, публичные интересы, частные интересы, благоприятная окружающая среда, способы возмещения вреда. Keywords: Civil responsibility, environmental harm, environment, losses, natural restitution, reimbursement of losses, public interests, private interests, methods of compensation.
\end{abstract}

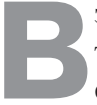

эколого-правовой науке и правоприменительной практике возмещение вреда, причиненного окружающей среде, традиционно рассматривается как применение мер гражданско-правовой ответственности. Вместе с тем, признается и наличие определенных особенностей реализации этого вида юридической ответственности применительно к экологическим отношениям. Указанное позволяет говорить о комплексном характере института возмещения экологического вреда, включающего нормы гражданского и экологического (природоресурсного) законодательства, которые соотносятся как общие и специальные. Общие нормы, к которым относятся основания и условия гражданско-правовой деликтной ответственности, принципы ее применения, содержатся в гражданском законодательстве (ст. 15, гл. 59 ГК РФ). К числу специальных норм, установленных Федеральным законом «Об охране окружающей среды» можно отнести: возможность использования специальных такс и методик при определении размера вреда природной среде; удлиненный срок исковой давности - 20 лет; определение субъектов, имеющих право предъявлять иски о возмещении вреда природной среде; обязанность возмещения субъектом хозяйственной деятельности правомерного вреда, то есть даже при наличии положительного заключения государственной экологической экспертизы на проект.

Достаточно ли этих специальных норм? Каковы должны быть пределы действия гражданского законодательства в регулировании отношений по возмещению экологического вреда? Эти вопросы весьма активно обсуждаются на страницах юридической литературы.
Как правило, необходимость в специальном правовом регулировании обосновывается исследователями спецификой экологического вреда. Известно, что указанный вред имеет сложную структуру, он по-особому проявляется во времени и пространстве. Все составные части природной среды находятся между собой во взаимодействии и взаимосвязи, они составляют единую экосистему, а в пределах конкретных участков суши или водоемов образуют единую общность организмов, растительности и т.П. - биоценоз. Причинение вреда одной из частей экосистемы немедленно отражается на состоянии других. Измененное вследствие причиненного вреда качество природной среды в свою очередь отрицательно воздействует на социальную среду: наносится вред здоровью людей, имуществу. Очень часто экологический вред представляет собой необратимые негативные последствия (уничтожение природного объекта, исчезновение вида флоры или фауны и т.п.). Потери в природной среде характеризуются как невосполнимые, относительно восполнимые или трудновосполнимые, воспроизводство которых связано с длительным периодом времени [14, с.152]. В связи с этим крайне трудным является процесс стоимостной оценки экологического вреда, выработка его критериев и показателей. Сложность оценки заключается еще и в том, что помимо вполне измеряемого материального вреда, гораздо большее значение в этой величине потенциально составляет нематериальная составляющая, которая может проявляться в ухудшении этических, эстетических или иных качеств объектов окружающей среды, что ущемляет интересы не только ныне живущих, но и будущих поколений. Исходя из этого, 
DOI: $10.7256 / 1811-9018.2014 .12 .13789$

При цитировании этой статьи сноска на dоi обязательна

\section{Право и политика $12(180) \cdot 2014$}

традиционные гражданско-правовые способы оценки вреда не могут полностью удовлетворить потребности защиты экологических прав и интересов общества [7, с.11-15].

Заметим, что особенности экологического вреда нашли свое признание не только в эколого-правовой доктрине, но и в судебной практике. Так, Высший Арбитражный Суд РФ неоднократно в своих решения подчеркивал, что «при определении экологического вреда в денежном выражении подлежат учету не только затраты на восстановление нарушенной природной среды, но и экологические потери, которые невосполнимы или трудновосполнимы» (Определение ВАС РФ от 12.03.2014 № ВАС-2194/14 по делу № А75-4538/2012). По мнению как теоретиков, так и практиков эту проблему можно решить применением специальных такс и методик оценки экологического вреда, исходя из этого, важнейшим направлением научных исследований должно стать их совершенствование $[5,11,10]$. Не отрицая важности данного направления, следует все же заметить, что оно лежит скорее в области естественнонаучных и экономических исследований, нежели правовых.

Более плодотворным является анализ категории «экологический вред» с позиции охраняемых законом интересов. На необходимость использования такого подхода при исследовании института возмещения вреда указывали Г.А Мисник [10, с.32-35], М.М. Бринчук [3, с. 16-23].

В классическом - цивилистическом - понимании вред представляет собой всякое умаление того или иного личного (нематериального) или имущественного (материального) блага [6, с. 329]. От вреда следует отличать убытки, под которыми чаще всего поразумевают денежную оценку имущественных потерь (вреда). Как пишет Ю.Н. Андреев, «возмещение ущерба (вреда) возможно в натуральном или денежном виде. Когда невозможно применить первый способ возмещения ущерба (вреда), приходится говорить о возмещении (взыскании) убытков в денежном выражении... Поэтому не случайно п. 1 ст. 393 ГК РФ возлагает на должника обязанность возместить потерпевшему (кредитору) убытки, причиненные неисполнением обязательства (в нашем случае деликтного)» [1, с.85].

Анализ причиненного вреда позволяет установить, чьи имущественные или личные неимущественные интересы (блага) были нарушены. Иными словами, определить, кто является в деликтном обязательстве потерпевшим (кредитором) в материально-правовом смысле и надлежащим истцом - в процессуально-правовом.

При нарушении требований экологического законодательства вред причиняется природной среде, ее отдельным компонентам, однако отнюдь не природная среда является «потерпевшей стороной» и адресатом возмещения[13, с.31]. Компоненты природной среды выступают объектом прав и законных интересов субъектов экологического права - граждан, организаций, государства и других публично-правовых образований, а также общества в целом.

В этом плане природная среда является весьма специфическим объектом, поскольку выступает одновременно объектом и публичных неимущественных интересов, и частных имущественных прав природопользователей. В действующем законодательстве это, пожалуй, наиболее четко отражено в Земельном кодексе РФ, который гласит, что регулирование отношений по использованию и охране земли осуществляется исходя из представлений о земле как
(1) о природном объекте, охраняемом в качестве важнейшей составной части природы, природном ресурсе, используемом в качестве средства производства в сельском хозяйстве и лесном хозяйстве и основы осуществления хозяйственной и иной деятельности на территории Российской Федерации, и одновременно как (2) о недвижимом имуществе, об объекте права собственности и иных прав на землю (п.1 ст.1). Соответственно, экологическое правонарушение одновременно посягает на частные и публичные интересы, носителем которых являются разные лица.

В свое время это очень четко обозначил В.В. Петров. Рассматривая правовые формы возмещения экологического вреда, он подразделил вред, возникающий вследствие нарушения природоохранительного законодательства, на экономический (посягающий на имущественные интересы природопользователей, в том числе собственников), экологический (посягающий на экологические интересы общества в чистой, здоровой, продуктивной, генетически многообразной природной среде обитания), антропологический (посягающий на здоровье человека (физиологический вред) и состояние будущих поколений (генетический вред)) [14, с.151-154]. Заметим, что «экономический» и «экологический» вред, по терминологии В.В. Петрова, - это по сути один и тот же вред, выразившийся в уничтожении или загрязнении природной среды, ухудшении ее качественных характеристик.

При нарушении имущественных прав природопользователей последние вправе предъявить требования о возмещении убытков. Так, ст. 62 ЗК РФ предусматривает возможность возмещения убытков, причиненных нарушением прав собственников земельных участков, землепользователей, землевладельцев и арендаторов. Причем в случае нахождения земельного участка в аренде, возникает конкуренция прав - арендодателя (собственника) и арендатора.

При нарушении же публичных прав в сохранении благоприятной окружающей среды согласно Федеральному закону «Об охране окружающей среды» требования о возмещении вреда вправе предъявить органы государственного экологического надзора Российской Федерации и субъектов РФ (ст. 5, 6, 66), граждане (ст. 11), общественные экологические организации (ст. 12), а также прокуроры в порядке, установленном ч. 1 ст. 45 ГПК РФ. Все перечисленные лица, в том числе отдельные граждане, в этом случае выступают в защиту неопределенного круга лиц - то есть любого и каждого, чье конституционное право на благоприятную окружающую среду нарушено (ст. 42 Конституции РФ). Специфика последнего как раз и заключается в том, что его носителями являются не только отдельные индивидуумы, но и общество в целом, соответственно, нарушение права одного человека на благоприятную окружающую среду одновременно является нарушением экологических публичных интересов[4]. Взысканные суммы в силу ч. 2 п. 6 ст. 46 Бюджетного кодекса РФ подлежат зачислению в бюджеты муниципальных районов, городских округов, городов федерального значения Москвы и СанктПетербурга по месту причинения вреда окружающей среде, которые и являются выгодоприобретателями по данным требованиям.

Закономерно возникает вопрос, защита чьих интересов - правообладателей на земельный участок или общества является приоритетной? Как правило, при предъявлении исков о возмещении вреда природопользователями, суды отказывают 
DOI: $10.7256 / 1811-9018.2014 .12 .13789$

При цитировании этой статьи сноска на dоі обязательна

Человек и окружающая среда

им в удовлетворении исковых требований на том основании, что у природопользователя отсутствуют право на обращение в суд с требованием о возмещении вреда, причиненного природным объектам (Постановление ФАС Западно-Сибирского округа от 04.06.2009 № Ф04-3104/2009(7368-А75-9) по делу № A75-5701/2008). Одновременно, удовлетворяя требования государственных органов в защиту общественных интересов, игнорируют тот факт, что природный объект находится в пользовании частных лиц (Постановление ФАС Московского округа от 12.08.2013 по делу N A40-14735/12-120-136). В юридической литературе на это счет высказываются разные точки зрения.

По мнению Л.Н. Бабенко, нельзя отрицать существование у природопользователя самостоятельного имущественного интереса, связанного с восстановлением земельного участка для дальнейшего использования. Такой подход противоречит смыслу законодательного регулирования земельных отношений, направленного на защиту не только публичных интересов, но также имущественных прав и интересов землепользователей [2, с.5].

М.М. Бринчук, напротив, считает, что «регулируемый и охраняемый экологическим законодательством интерес к сохранению благоприятной окружающей среды, экологического благополучия относится к публичным интересам, подлежащим приоритетной правовой защите». По его мнению, данная задача и правовой принцип со всей очевидностью вытекают из нормы, установленной в ст. 9 Конституции РФ: земля и другие природные ресурсы используются и охраняются в Российской Федерации как основа жизни и деятельности народов, проживающих на соответствующей территории. Более того, ученый делает вывод, что в случае нарушения упомянутых охраняемых публичных экологических интересов, должна применяться не гражданско-правовая (имущественная), а иная юридическая ответственность, которую он предлагает именовать эколого-правовой [3, с. 17]. Данная идея является весьма интересной, однако нуждается в дальнейшем развитии.

Представляется, что признание возмещения вреда, причиненного публичным экологическим интересам, особым видом юридической ответственности, не исключает возможность применения норм гражданского законодательства. В то же время необходимо более четко определить пределы его действия с тем, чтобы обеспечить баланс частных и публичных интересов. Общим знаменателем здесь должно выступать социальное назначение эколого-правового института возмещения вреда природной среде, которое заключается в восстановлении нарушенного состояния природных объектов [12, с. 92]. Достижение указанной цели, конечно, с определенными оговорками, так как могут иметь место трудновосполнимые и невосполнимые потери в природной среде, позволит удовлетворить интересы и природопользователей, и общества.

Как нам представляется, в случае нарушения публичных экологических интересов следует ограничить возможность применения такого способа защиты прав как возмещение убытков, поскольку он не обеспечивает восстановления нарушенного состояния природных объектов. Это связано с тем, что действующее законодательство не содержит никаких механизмов контроля за расходованием средств, взысканных с причинителей вреда природной среде. Как говорилось выше, указанные средства в соответствии с бюджетным законодательством поступают в местные бюджеты и не имеют целевого назначения. Отсутствует какая-либо зависимость между поступающими средствами и затратами муниципальных образований на осуществление природоохранных мероприятий. На это не раз обращалось внимание исследователями. Г.А Мисник пишет: «Одним из недостатков законодательства является отсутствие норм, обеспечивающих целевой режим использования средств, полученных в порядке возмещения экологического вреда» [10,с. 35].

Как верно пишет Е.А. Сухова, «невозможность проследить использование конкретной суммы, взысканной за конкретное правонарушение, на восстановление нарушенного права свидетельствует, что гражданско-правовая ответственность практически утрачивает свою компенсационную функцию» $[15$, с.87]. Заметим, что такое положение вещей делает, в общем-то, бессмысленными все рассуждения теоретиков и практиков о трудностях оценки вреда окружающей среде, отсутствии методического единства его оценки, невозможности из-за комплексности вопроса предложить универсальную методику оценки ущерба и пр. И.О. Краснова также, акцентируя внимание на этой проблеме, отмечает, что в итоге взысканная компенсация превращается в чистый доход государства, которое становится заинтересованным лицом в поддержании условий для несоблюдения экологического законодательства $[8$, с. 32]. В итоге главная функция института возмещения убытков - восстановительно-компенсационная - трансформируется в карательную, поскольку только ущемляет имущественную сферу причинителя вреда, но не восстанавливает нарушенные права потерпевших (ни общества и пользователей). Полагаем, что справедливое наказание (кару) за совершенное экологическое правонарушение более эффективно могут обеспечить другие виды ответственности - административная и уголовная.

Более того, взыскание убытков в пользу муниципального образования не освобождает природопользователей от выполнения природоохранных мероприятий, в том числе по восстановлению их нарушенного состояния. В связи с этим природопользователи не только не получают компенсацию за снижение стоимости принадлежащего им имущества - природных ресурсов, но и сами несут затраты на восстановление. Следует подчеркнуть, что указанные требования к правообладателям земельных участков нельзя рассматривать как возложение гражданско-правовой ответственности за вред, причиненный природной среде. В данном случае речь идет о понуждении к выполнению природоохранных обязанностей, вытекающих из закона или договора. Из этого следует и еще один важный вывод: при невыполнении собственниками (природопользователями) обязанностей, вытекающих из закона или договора, нет оснований для привлечения их к деликтной ответственности. Такие иски удовлетворяются ошибочно (Постановление ФАС Восточно-Сибирского округа от 06.05.2011 по делу N А33-11338/2010).

Учитывая изложенное, предлагаем закрепить в Федеральном законе «Об охране окружающей среды» правило, согласно которому вред окружающей среде, причиненный нарушением законодательства в области охраны окружающей среды, возмещается исключительно посредством возложения на ответчика обязанности по восстановлению нарушенного состояния окружающей среды за счет 
DOI: $10.7256 / 1811-9018.2014 .12 .13789$

При цитировании этой статьи сноска на dоі обязательна

\section{Право и политика $12(180) \cdot 2014$}

его средств в соответствии с проектом восстановительных работ. Натуральная реституция должна стать не просто приоритетным способом возмещения вреда, как предлагает Г.А. Мисник [9, с. 15], а единственно возможным в тех случаях, когда требования заявляются в публичных интересах. Объем необходимых работ и степень восстановления природных объектов должен определять суд на основании доказательств, представляемых ответчиком.

Как верно отмечает А.Л. Иванова, в процессе выбора способа возмещения экологического ущерба важно учитывать, что природная среда является динамичным, постоянно меняющимся объектом. Конечным результатом натуральной реституции могут быть: а) восстановление первоначального состояния объекта, б) восстановление состояния, которое могло бы быть достигнуто при естественном развитии событий; в) просто исправление явных негативных последствий. При этом значимо в социальном и экономическом плане, чтобы цель осуществляемых в ходе процесса возмещения экологического вреда мероприятий определялась в каждом конкретном случае с учетом характеристик природного объекта и произошедшего[7, с. 14].

Конечно, возникает вопрос, как же быть в том случае, если проведение восстановительных мероприятий невозможно в принципе, либо ответчик не имеет реальной возможности их провести? Думается, в такой ситуации речь должна идти о возмещении убытков, рассчитанных на основе такс и методик, но не в пользу государства или муниципального образования (как это предусматривает действующее законодательство), а в пользу собственников природных объектов. Исковые требования могут быть заявлены самими собственниками, природопользователями, а также уполномоченными ими лицами.

Так, при нахождении природного объекта в федеральной собственности (а это подавляющая часть природных объектов на сегодня), иски могут быть заявлены органами государственной власти, на которых возложены обязанности по охране и воспроизводству пострадавших природных объектов. Например, согласно ст. 83 ЛК РФ обязанностями по организации охраны, защиты и воспроизводства лесов, расположенных на землях лесного фонда, наделены органы исполнительной власти субъектов РФ. Данное правило должно сопровождаться установлением принципа целевого использования бюджетных средств, поступающих по искам о возмещении вреда природной среде. Передача природоохранных обязанностей природопользователям должна влечь и передачу права на защиту от посягательств третьих лиц. Тот же ЛК РФ предусматривает, что санитарно-оздоровительные мероприятия (вырубка погибших и поврежденных лесных насаждений, очистка лесов от захламления, загрязнения и иного негативного воздействия) на лесных участках, предоставленных в аренду, осуществляются арендаторами этих лесных участков на основании проекта освоения лесов (ст. 55).

Если причинитель вреда уже добровольно понес затраты на полное или частичное восстановление нарушенного состояния природных объектов, они должны учитываться судом при решении вопроса о сумме убытков, присуждаемых в пользу правообладателя природного объекта. Отметим, что судебная практика по данному вопросу весьма противоречива, зачастую суды при предъявлении требований о возмещении убытков эти затраты не учитывают (Постановление ФАС Западно-Сибирского округа от 05.11.2013 по делу № A75-4538/2012; Постановление ФАС Волго-Вятского округа от 31.01.2014 по делу № А38-8658/2012; Постановление Восьмого арбитражного апелляционного суда от 11.10.2012 по делу № A75-3357/2012). Более того, указывают, что при возмещении вреда, причиненного природной среде, на лицо, причинившее вред, возлагается двойная обязанность: устранить нарушение (т.е. добровольно провести работы по восстановлению нарушенного состояния природного объекта) и возместить вред (т.е. убытки в денежной форме, рассчитанные по таксам и методикам). Например, такая правоприменительная практика в Западно-Сибирском арбитражном округе признается сложившейся (Постановление Восьмого арбитражного апелляционного суда от 30.08.2013 по делу № А81-950/2013).

Проведение собственниками природных объектов (природопользователями) мероприятий по устранению вреда, причиненного действиями третьих лиц, является основанием предъявления требований о возмещении произведенных затрат на общих основаниях в соответствии с требованиями гражданского законодательства. Основания для применения в таких случаях специальных - экологических - норм, по нашему мнению, отсутствуют. При определении размера убытков должны приниматься во внимание реально произведенные затраты на основе представленных истцом доказательств, а не таксы и методики.

Полагаем, что внедрение этих предложений в законодательство и практику позволят обеспечить баланс частных и публичных экологических интересов и повысить эффективность института возмещения экологического вреда.

\section{Библиография:}

1. Андреев Ю.Н. Ответственность государства за причинение вреда: цивилистические аспекты. СПб., 2013.-374 с.

2. Бабенко Л.Н. Земельные правонарушения как основание гражданско-правовой ответственности // Арбитражный и гражданский процесс. 2010. № 2. С. 2-7.

3. Бринчук М.М. Так существует ли эколого-правовая ответственность? // Экологическое право. 2009. № 2/3. Специальный выпуск. С. 16-23.

4. Васильева М.И. Публичные интересы в экологическом праве. М.: Изд-во МГУ, 2003. -424 с.

5. Глибко О.Я., Лукин А.А. Правовые основы оценки и возмещения экологического ущерба в Российской Федерации // Российский юридический журнал. 2011. № 4. С. 201-210.

6. Грибанов В.П. Осуществление и защита гражданских прав. М., 2000. - 411 с.

7. Иванова А.Л. Возмещение экологического вреда: сравнительно-правовой анализ европейского, немецкого и российского права: Автореф. дис. ... канд. юрид. наук. М., 2006. - 25 с.

8. Краснова И.О. Правовое регулирование возмещения экологического вреда // Экологическое право. 2005. № 4. С. 26-33. 
DOI: $10.7256 / 1811-9018.2014 .12 .13789$

При цитировании этой статьи сноска на доі обязательна

Человек и окружающая среда

9. Мисник Г.А. Принципы гражданско-правовой ответственности за причинение экологического вреда // Экологическое право. 2008. № 2. С. 14-20.

10. Мисник Г.А. Возмещение экологического вреда в российском праве. Автореф. дис. ...докт. юрид. наук. М., $2008 .-56$ с.

11. Моторин Е.П. Правовые проблемы оценки вреда в сфере природопользования // Общество и право. 2011. № 1. С. 80-83.

12. Мухина И.Д. Гражданско-правовые деликты в сфере природопользования: Дис. ... канд. юрид. наук. Краснодар, 2004.-196 с.

13. Никишин В.В. Теоретические проблемы возмещения экологического вреда: идеи В.В. Петрова и современность // Экологическое право. 2009. № 2/3. Специальный выпуск. С. 28-32.

14. Петров В.В. Правовая охрана природы в СССР. М., 1984.-384 с.

15. Сухова Е.А. Гражданско-правовая ответственность за правонарушения в области охраны и использования земель: анализ законодательства и практики // Законодательство и экономика. 2006. № 7. С. 80-87.

16. Куракин И.А. Теоретико-правовой анализ норм Гражданского кодекса РФ, регламентирующих наступление ответственности при правомерном причинении вреда // Политика и Общество. 2011. 7. С. 39-44.

\section{References (transliterated):}

1. Andreev Yu.N. Otvetstvennost' gosudarstva za prichinenie vreda: tsivilisticheskie aspekty. SPb., 2013.-374 s.

2. Babenko L.N. Zemel'nye pravonarusheniya kak osnovanie grazhdansko-pravovoi otvetstvennosti // Arbitrazhnyi i grazhdanskii protsess. 2010. № 2. S. 2-7.

3. Brinchuk M.M. Tak sushchestvuet li ekologo-pravovaya otvetstvennost'? // Ekologicheskoe pravo. 2009. № 2/3. Spetsial'nyi vypusk. S. 16-23.

4. Vasil'eva M.I. Publichnye interesy v ekologicheskom prave. M.: Izd-vo MGU, 2003. - 424 s.

5. Glibko O.Ya., Lukin A.A. Pravovye osnovy otsenki i vozmeshcheniya ekologicheskogo ushcherba v Rossiiskoi Federatsii // Rossiiskii yuridicheskii zhurnal. 2011. № 4. S. 201-210.

6. Gribanov V.P. Osushchestvlenie i zashchita grazhdanskikh prav. M., 2000. - $411 \mathrm{~s}$.

7. Ivanova A.L. Vozmeshchenie ekologicheskogo vreda: sravnitel'no-pravovoi analiz evropeiskogo, nemetskogo i rossiiskogo prava: Avtoref. dis. ... kand. yurid. nauk. M., 2006. -25 s.

8. Krasnova I.O. Pravovoe regulirovanie vozmeshcheniya ekologicheskogo vreda // Ekologicheskoe pravo. 2005. № 4. S. 26-33.

9. Misnik G.A. Printsipy grazhdansko-pravovoi otvetstvennosti za prichinenie ekologicheskogo vreda // Ekologicheskoe pravo. 2008. № 2. S. 14-20.

10. Misnik G.A. Vozmeshchenie ekologicheskogo vreda v rossiiskom prave. Avtoref. dis. ...dokt. yurid. nauk. M., $2008 .-56$ s.

11. Motorin E.P. Pravovye problemy otsenki vreda v sfere prirodopol'zovaniya // Obshchestvo i pravo. 2011. № 1. S. 80-83.

12. Mukhina I.D. Grazhdansko-pravovye delikty v sfere prirodopol'zovaniya: Dis. ... kand. yurid. nauk. Krasnodar, 2004.-196 s.

13. Nikishin V.V. Teoreticheskie problemy vozmeshcheniya ekologicheskogo vreda: idei V.V. Petrova i sovremennost'// Ekologicheskoe pravo. 2009. № 2/3. Spetsial'nyi vypusk. S. 28-32.

14. Petrov V.V. Pravovaya okhrana prirody v SSSR. M., 1984.-384 s.

15. Sukhova E.A. Grazhdansko-pravovaya otvetstvennost' za pravonarusheniya v oblasti okhrany i ispol'zovaniya zemel': analiz zakonodatel'stva i praktiki // Zakonodatel'stvo i ekonomika. 2006. № 7. S. 80-87.

16. Kurakin I.A. Teoretiko-pravovoi analiz norm Grazhdanskogo kodeksa RF, reglamentiruyushchikh nastuplenie otvetstvennosti pri pravomernom prichinenii vreda // Politika i Obshchestvo. 2011. 7. C. 39-44. 